\title{
Risk Factors and Prognostic Index of Perioperatory Complications in The
}

\section{Laparoscopic Vertical Gastroplication}

\section{Labrada Despaigne, Alberto* | Tamargo Barbeito, Teddy Osmin | Martínez Ortiz, Luis Alberto}

*Correspondence: Labrada Despaigne, Alberto,

Address: Department of Anaesthesia, "General Calixto García" University Hospital. Faculty of Medical Sciences "General Calixto García". Havana. Cuba

e-mail $₫:$ albert@infomed.sld.cu

Received: 10 February 2021; Accepted: 15 February 2021

Copyright: (C) 2021 Labrada. This is an open-access article distributed under the terms of the Creative Commons Attribution License, which permits unrestricted use, distribution, and reproduction in any medium, provided that the original work is properly cited.

\section{ABSTRACT}

Introduction: The obese patient who is treated with laparoscopic bariatric surgery is complex for the anesthesiologist because of its anatomofunctional characteristics and associated diseases. Objective: To identify the presence of perioperative complications and their relationship with preoperative factors and intraoperative anesthetic behavior that may constitute indicators of prediction of complications. Materials and Methods: An analytical, observational, longitudinal, retrospective study was carried out in 476 obese patients surgically operated by laparoscopic vertical gastroplication. Immediate intraoperative and postoperative clinical complications and their relationship with demographic, clinical, anthropometric and anestheticdependent variables were identified, which constituted risk factors. With the risk factors identified, a prognostic index was constructed and subsequently validated. Results: The immediate intraoperative and postoperative complications were few. It was possible to identify three independent risk factors, given by the previous respiratory functional status, the anesthetic technique used and the surgical time. A prognostic index of complications was constructed that grouped patients at low, intermediate and high risk of presenting complications. Conclusions: The grouping of risk factors as a predictive index of complications was effective because the complication prediction capacity could be estimated and validated.

Keywords: Obesity, Risk Factor, Vertical Gastroplication, Laparoscopic Bariatric Surgery

\section{Introduction}

Obesity in a patient makes anesthesia difficult and dangerous, as well as complicating the technique. This condition places the obese at a clear disadvantage compared to the normal patient from a medical, diagnostic and practical point of view (de la Matta et al., 2014). This determines that it is of 
primary importance to identify the pathophysiological changes that obesity produces, as well as the anesthetic implications within the scope of bariatric surgery, in order to make anesthetic-surgical results as favorable as possible (Labrada, 2012).

Laparoscopic bariatric surgery is, according to multiple research carried out worldwide (Wadden et al., 2014; Zerrweck et al., 2015), the best therapeutic option for the obese patient, but its performance presents a series of difficulties for the anesthesiologist, derived both from the treatment of a patient with anatomical alterations and that is organically affected, as per the peculiarities of the laparoscopic technique that differentiate it from conventional or "open" surgery (Antoniou et al., 2015; Blikkendaal et al., 2015; Markar et al., 2019; Tian et al., 2011; Tinelli et al., 2014; Mason et al., 2012; Corneille et al., 2007).

There are a large number of elements that have been described as risk factors for complications and mortality in the obese patient, such as: degree and duration of obesity, body fat distribution (abdominal obesity), associated cardiovascular dysfunction (ischemic heart disease, arterial hypertension, arrhythmias), obstructive sleep apnea syndrome, chronic obstructive pulmonary disease, conventional surgery, smoking and complex surgical techniques (Abete et al., 2015; Arance et al., 2015; Ryo et al., 2014; Elffers et al., 2017; Gupta et al., 2012). Many of them vary between one author and another, mainly due to the variety of surgical techniques and experience of the group dedicated to perioperative care of these patients.

In a meta-analysis by Buchwald, et al. (2004) the mortality of the adjustable gastric band (AGB) was $0.1 \%$, that of the Roux-en-Y gastric bypass (GBP) $0.5 \%$ and the bilio-pancreatic bypass with duodenal switch $1.1 \%$. Mortality in bariatric surgery is significantly lower than in other surgical procedures. A review of US hospitals found mortality of $9 \%$ for esophagectomy, 8.3\% for pancreatectomy, 3.5\% for coronary bypass and 3,9\% for aortic aneurysm (Dimick et al., 2004).

According to the meta-analysis by Reoch, et al. (2011) the factors that increase the risk of mortality are the presence of anastomosis leakage, pulmonary embolism (PE), arterial hypertension and weight prior to surgery. The main cause of death in $75 \%$ of cases is anastomosis leak, followed by PE in $25 \%$.

Ribaric G, et al. (2014) states that the risk of mortality associated with bariatric surgery in the first year is less than $1 \%$, and $6 \%$ at five years. However, mortality is lower than in patients with similar body mass index (BMI) who are not treated by bariatric surgery. The leading cause of death is coronary heart disease. Some characteristics, such as advanced age, a higher BMI, open surgery and being 
hispanic or african-american are associated with an increased risk of developing postoperative complications (Ryo et al., 2014; Gupta et al., 2012; Sudan et al., 2014).

However, most of the studies published in the scientific literature only analyze those immediate or long-term complications that depend on the surgical technique (in-line suture hemorrhage, fistula, stenosis, suture dehiscence and ulcers among others) (Puzziferri et al., 2014; Courcoulas et al., 2018; Builes et al., 2019) and they do not refer to clinical complications such as those analyzed in the present investigation.

For this reason it is necessary to deepen the intraoperative and immediate postoperative anesthetic treatment in terms of perioperative complications and identification of risk factors in the obese population that is intervened by bariatric procedures; and in this way be able to create scales of prognostic indices, typical of the Cuban population and with the resources available.

The objective of the present investigation was to identify the presence of perioperative complications and their relationship with preoperative factors and intraoperative anesthetic behavior that may constitute predictive or warning indicators of said complications during laparoscopic bariatric surgery.

\section{Materials and Methods}

An observational, analytical, retrospective cohort investigation was performed in obese patients surgically operated by means of laparoscopic vertical gastroplication at the University Hospital "General Calixto García”, between January 2005 and December 2016. The universe consisted of obese patients with the following inclusion criteria: patients with established obesity at less than 5 years, of any gender, over 20 years old, who attended the consultation in order to be surgically operated by laparoscopic bariatric surgery and who gave their consent to participate in the investigation. Patients with a history of alcoholism or drug addiction, with portal hypertension, psychiatric patients, patients with inflammatory bowel disease, chronic pancreatitis, liver cirrhosis or cancer and pregnant patients were excluded, according to the protocol of the anesthesia service. The sample of 476 patients was randomly divided into two groups: estimation group (EG) with 239 patients and validation group (VG) with 237 patients by means of an option that the SPSS statistical program. The dependent variable was the presence of complications, and the independent variables were: age, gender, body mass index (BMI), degree of obesity, waist circumference (WC), hip perimeter, waist/hip index (W/H I), physical condition, associated diseases, respiratory functional tests (RFT), anesthetic technique and time surgical. The latter were analyzed in each group to demonstrate similarity between them and ensure 
that they can be compared.

The qualitative variables were summarized with percentages and absolute numbers and the quantitative variables with the mean and their standard deviation (SD). For the comparison of groups according to qualitative variables, the chi-square test $(\chi 2)$ was used with correction as appropriate. In the case of contingency tables of two dichotomous qualitative variables, if there were $25 \%$ or more expected frequencies less than 5, the alternative of Fisher's exact test was used. In the presence of an ordinal variable with another qualitative dichotomous one, Bartholomew's chi-square test $(\chi 2)$ was used. For the comparison of means in samples that did not have a normal distribution, the MannWhitney U test was used and, otherwise, the Student's t test. In all hypothesis tests, a significance level of 0.05 was set.

With the first group (EG), logistic regression functions were estimated for the factors that influence the occurrence of complications. In order to evaluate the existence of an excessive association between the independent variables (collinearity) that introduced inaccuracies in the estimates, the association between them with the $\chi 2$ homogeneity test (Chi Square), accompanied by a Phi correlation coefficient was evaluated. There was no correlation above 0.80 . The multivariate analysis was based on the adjustment of a logistic regression model with all variables and according to the $\chi 2$ omnibus statistic ( $\mathrm{p}<0.001)$ it was significant. Subsequently using the Wald statistic, those variables whose coefficients were significantly different from $0(\mathrm{p}<0.05)$ were identified, in addition, the odds ratios $(\mathrm{OR})$ were estimated on time and by intervals for each variable $(\exp (b i))$ selected. The predictability of the model was evaluated and checked in the validation group. The statistical test of Hosmer and Lemeshow was performed to assess the quality of the regression adjustment (calibration).

With the function obtained in the EG, the probability of presenting complications was calculated for each patient and an ROC (Receiver Operating Characteristic) curve was constructed with the purpose of assessing discrimination, which was done with the calculation of the area under the curve (AUC) with its 95\% confidence interval and by the visual examination of the curve (while further away from the axis of the abscissa, exceeding the bisector of the first quadrant where those points of a positive test would remain or refusal by chance, the function for prediction will be more effective).

In the validation group (VG), the probabilities of complications for each patient were also calculated and another ROC curve was constructed to assess the ability to discriminate using the AUC and with the aforementioned Hosmer-Lemeshow test the calibration was assessed. With the idea of obtaining an index that had a greater practical value, a prognostic index was constructed from the 
coefficients obtained for each variable in the logistic regression function as follows: $\mathrm{I}=\mathrm{w} 1 \mathrm{x} 1+\mathrm{w} 2 \mathrm{x} 2+\ldots$ + wkxk

Where wk means the value of the coeficent and $\mathrm{Xk}$ the value of each variable in each patient, so that the aforementioned index was with the following formula:

$\mathrm{PI}=\quad 0.2 \mathrm{xmale} \quad$ sex-0.5xpathological $\mathrm{W} / \mathrm{H} \quad \mathrm{I}+1.5 \mathrm{xabnormal}$ respiratory functional tests-0.5xDM-
$1.1 \mathrm{xOSAS}+0.5 \mathrm{xhyp}$ ercholesterolemia+0.6*MS+2.6xtime surgical $>2 \mathrm{hours}-1.8 \mathrm{xTIVA}+0.1 \mathrm{xBMI} \geq 40 \mathrm{Kg} / \mathrm{m}^{2}$

Once the score value was obtained for each patient, another ROC curve was constructed and the AUC calculated to see its discriminatory capacity.

Finally, the empirical distribution of the index values was divided in the validation sample. These three zones would be delimited by the empirical 33.3 and 66.6 percentiles that divide the possible range of values into three equal zones. In this way, a first zone would be delimited between the lowest value $(-1.40)$ and the 33.3 percentile that would be a low risk area for complications, an intermediate zone between the 33.3 percentile $(-1.40)$ and $66.6(0.484)$ that would be of medium risk that could be called doubtful, "gray zone" or intermediate and above the 66.6 percentile $(>0.484)$ would be the area with the highest risk of complications. By way of (conceptual) validation of these divisions, the percentage of complications for each zone was calculated and it was evaluated whether there were differences between these percentages by means of the Bartholomew chi $(\chi 2)$ square test. It would be expected to find the highest frequency of complications in the high risk zone and the lowest frequency in the low risk zone.

\section{Results}

Of the total of patients studied, $71.3 \%$ presented a BMI greater than or equal to $40 \mathrm{Kg} / \mathrm{m} 2$ that is, classified as morbidly obese.

The two groups were similar in relation to age and gender distribution. The average age was 38.3 \pm 8.6 , with a majority between 20 and 49 years. There was a predominance of female sex in $63.9 \%$ of patients. The overall average BMI of the total of patients was $45.4 \pm 9.0$, the waist circumference had a mean in the total sample of $132.7 \pm 15.7$. In all cases, values above those accepted as normal were observed, a matter to be expected since all the patients studied are obese. The majority of patients (68.7\%) presented a waist/hip index considered as pathological.

Most of the patients were classified as ASA II physical status (79.2\%), and the most frequent 
associated diseases were obstructive sleep apnea syndrome (32.6\%), arterial hypertension (29.6\%), diabetes mellitus (20.8\%), arthropathy (18.9\%) and hypercholesterolemia (15.1\%), to a lesser extent the metabolic syndrome (8.6\%) was identified, asthma bronchial (7.4\%) and ischemic heart disease (4.4\%). The results of respiratory functional tests showed a predominance of patients with normal functional tests in $82 \%$. In the estimation group the predominant pattern was $53.5 \%$ restrictive, followed by the obstructive pattern in $41.9 \%$ and in the validation group, with the same pattern predominance, it was $47.6 \%$ and $40,5 \%$, respectively.

In the total sample there were 40 complicated patients (8.4\%), predominantly in the intraoperative period followed by those who presented postoperative complications and only 3 of them had complications in both periods. There were no significant differences between the two groups (estimation and validation), in the latter there were 3 patients with complications in both periods (Table 1).

40 patients with complications presented a total of 63 complications, 32 during the intraoperative period and 31 in the immediate postoperative period. There were no differences between the two moments evaluated, however, during the intraoperative period, most of them were of cardiorespiratory origin, while in the postoperative period there were others such as nausea and vomiting that turned out to be the majority.

Table 1: Distribution of patients according to complications and study groups. HUGCG, 2005-2016

\begin{tabular}{|l|c|c|c|c|}
\hline Complications & Total $(\mathbf{n = 4 7 6})$ & Estimation $\mathbf{n}=\mathbf{2 3 9}$ & Validation $\mathbf{n = 2 3 7}$ & $\mathbf{p}$ \\
\hline Presents & $40(8,4 \%)$ & $18(7,5 \%)$ & $22(9,3 \%)$ & 0,601 \\
\hline Intraoperative & $21(52,5 \%)$ & $9(50,0 \%)$ & $12(54,5 \%)$ & 1,000 \\
\hline Postoperative & $19(47,5 \%)$ & $9(50,0 \%)$ & $10(45,5 \%)$ & \\
\hline Both periods & $3(7,5 \%)$ & $0(0,0 \%)$ & $3(13,6 \%)$ & 0,238 \\
\hline
\end{tabular}

Source: Clinical history.

Table 2 represents the results of the logistic regression in the search for prognostic factors for complications. The variables that independently influenced the likelihood of complications were three. The patients with abnormal respiratory function have four times more chance of having complications than those who have a function reserved or normal respiratory (OR 4.343). The patients with a surgical time greater than two hours have approximately 14 times more chance of having complications (OR 13.652), and the patients with total intravenous anesthesia (TIVA) are less likely to have complications than those who had balanced (reference category), since the OR is less than one, behaves as a protective factor. The OR for patients with balanced anesthesia is $6.211(1 / 0.161)$, that is, in those who were 
indicated a balanced anesthesia, complications were six times greater. The 95\% CI for the OR of the RFT and the surgical time was wide due to the small sample size.

Table 2: Results of the logistic regression for the search of prognostic factors for complications. HUGCG, 2005-2016

\begin{tabular}{|l|c|c|c|}
\hline \multicolumn{1}{|c|}{ Variables } & OR & IC de $\mathbf{9 5} \%$ & p \\
\hline Edad & 1,023 & $0,958-1,093$ & 0,501 \\
\hline Male Sex & 1,196 & $0,322-4,444$ & 0,789 \\
\hline Pathological W/H I & 0,626 & $0,160-2,451$ & 0,501 \\
\hline RFT abnormal a & 4,343 & $1,046-18,036$ & 0,043 \\
\hline Diabetes Mellitus & 0,586 & $0,096-3,597$ & 0,564 \\
\hline OSAS & 0,327 & $0,069-1,564$ & 0,162 \\
\hline Hypercholesterolemia & 1,580 & $0,342-7,266$ & 0,558 \\
\hline Metabolic syndrome & 1,765 & $0,281-11,071$ & 0,565 \\
\hline Surgical time ${ }^{\text {b }>\text { 2 horas }}$ & 13,652 & $2,776-67,149$ & 0,001 \\
\hline Type of anesthesia c & 0,161 & $0,027-0,966$ & 0,046 \\
\hline BMI $\geq 40 \mathrm{Kg} / \mathrm{m}^{2}$ & 1,072 & $0,566-4,372$ & 2,030 \\
\hline
\end{tabular}

OR: odds ratio, CI: confidence interval, a: normal RFT reference category, b: surgical time reference category less than or equal to two hours, c: balanced anesthesia reference category.

When calculating the probability using the logistic regression model in the validation sample, an AUC of 0.694 (95\% CI: 0.588-0.800; $\mathrm{p}=0.003$ ) was obtained, which evidences a good discrimination of the model between patients with and without complication (Fig. 1).

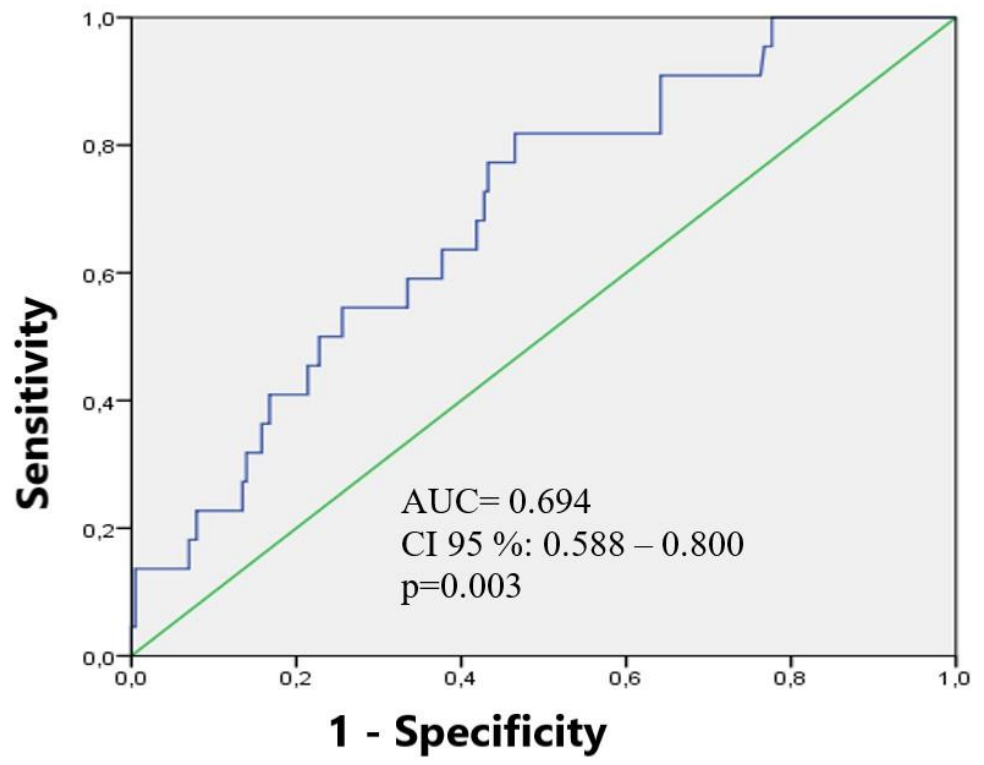

Figure 1: ROC curve for the value of the probability of having complication in the validation sample. 
When the proposed score was computed in the validation sample and the ROC curve was plotted, the $\mathrm{ABC}$ was 0.711 (95\% CI 0.607-0.815; $\mathrm{p}=0.001)$ (Fig. 2).

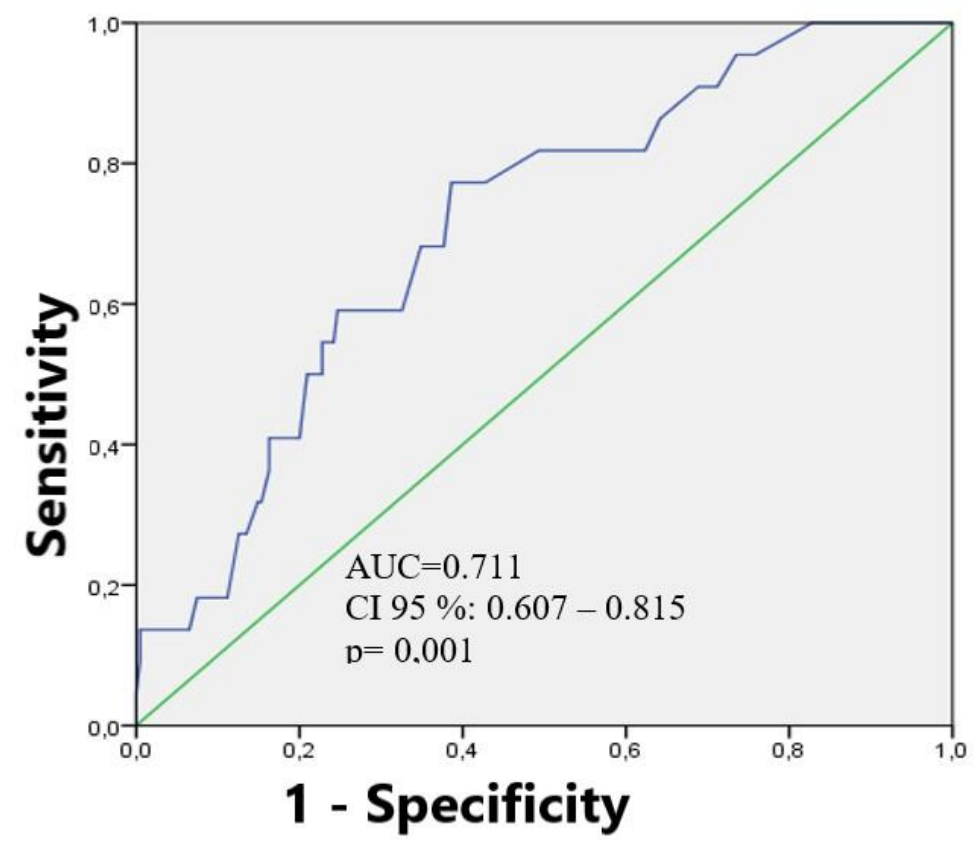

Figure 2: ROC curve of the prognostic index score for the presence of complications in the validation sample.

Table 3 shows different cut-off points for the prognostic index score in terms of sensitivity and specificity. For example, a value greater than or equal to 0.05 has a sensitivity of 0.773 and a specificity of 0.600 , that is, a value of the prognostic index greater than or equal to 0.05 , could predict $77.3 \%$ of patients who will actually have complications and $60.0 \%$ of those who will not have them. The cut-off value of 0.25 has a sensitivity of 0.682 and specificity of 0.651 , so before a value greater than or equal to 0.25 of the proposed indicator, $68.2 \%$ of patients who will actually have complications can be detected and $65.1 \%$ of those who will not present them.

Table 3: Sensitivity and Specificity for different cut-off points of the prognostic index with the validation sample. HUGCG, 2005-2016

\begin{tabular}{|c|c|c|c|}
$\begin{array}{c}\text { Cut-off points } \\
\text { (Positive if it is bigger than) }\end{array}$ & Sensitivity & Specificity & 1- Specificity \\
\hline $\mathbf{0 . 0 5}$ & 0.773 & 0.600 & 0.400 \\
\hline $\mathbf{0 . 1 0}$ & 0.773 & 0.605 & 0.395 \\
\hline $\mathbf{0 . 1 5}$ & 0.773 & 0.614 & 0.386 \\
\hline $\mathbf{0 . 2 0}$ & 0.773 & 0.614 & 0.386 \\
\hline $\mathbf{0 . 2 0}$ & 0.682 & 0.623 & 0.377 \\
\hline $\mathbf{0 . 2 5}$ & 0.682 & 0.651 & 0.349 \\
\hline
\end{tabular}


Table 4 summarizes the discrimination and calibration properties of the internal (EG) and external (VG) validation sample for the constructed index. The Hosmer-Lemeshow statistician in the two samples has an associated probability value greater than 0.05 , therefore there is a good calibration of this indicator and the two AUC were high, which affirms good discrimination.

Table 4: Summary of the results of calibration and discrimination of the model for the prognostic index. HUGCG, 2005-2016

\begin{tabular}{|c|c|c|c|c|c|}
\hline \multicolumn{1}{c}{ Validation } & \multicolumn{2}{c}{ Hosmer-Lemeshow } & \multicolumn{3}{c|}{ ABC } \\
\hline & $\mathbf{C}$ & $\mathbf{p}$ & Area & CI 95\% & p \\
\hline Internal (Estimation group) & 6.561 & 0.585 & 0.915 & $0.860-0.971$ & $<0.001$ \\
\hline External (Validation group) & 8.325 & 0.402 & 0.711 & $0.807-0.815$ & 0.001 \\
\hline
\end{tabular}

Table 5 shows the estimated coefficients of the logistic regression function to estimate the probability of having complications in bariatric surgery and weightings granted to each item on the scale.

The weighting values for each of the variables are the constants that are included in the formula for calculating the prognostic index. In the case of qualitative variables, they were categorized according to presence or not, in the first case with a value of 1 and in the second case with a value of 0 . In this way the complication prognosis can be calculated.

Table 5: Estimated coefficients of the Logistic Regression Function to estimate the probability of having complications in bariatric surgery and weightings granted to each item of the scale. HUGCG, 2005-2016

\begin{tabular}{|l|c|c|c|}
\hline \multicolumn{1}{c}{ Variables } & \multicolumn{1}{c|}{$\mathbf{b}^{\mathbf{a}}$} & $\mathbf{p}^{\mathbf{b}}$ & Ponderations \\
\hline Age & 0.023 & 0.501 & 0.0 \\
\hline Male sex & 0.179 & 0.789 & 0.2 \\
\hline Pathological W/H I & -0.468 & 0.501 & -0.5 \\
\hline RFT abnormal & 1.469 & 0.043 & 1.5 \\
\hline Diabetes mellitus & -0.534 & 0.564 & -0.5 \\
\hline OSAS & -1.116 & 0.162 & -1.1 \\
\hline Hypercholesterolemia & 0.450 & 0.558 & 0.5 \\
\hline Metabolic syndrome & 0.568 & 0.565 & 0.6 \\
\hline Time surgical > 2 hours & 2.614 & 0.001 & 2.6 \\
\hline Type of anesthesia ${ }^{c}$ & -1.829 & 0.046 & -1.8 \\
\hline BMI $\geq 40 \mathrm{Kg} / \mathrm{m}^{2}$ & 0.070 & 2.030 & 0.1 \\
\hline
\end{tabular}

a coefficient of each variable in the logistic regression function, $\mathbf{b}$ statistical significance, $\mathbf{c}$ balanced anesthesia reference category. 
With these values, patients can be classified as Low Risk (IP < -1.400), Medium Risk (IP -1.400 0.484) and High Risk (IP > 0.484)

Fig. 3 shows the distribution of patients according to risk category and the presence of complications in the validated sample. As the risk increases, the percentage of said event increases. Complicated patients were distributed in the low risk, $13.6 \%$, in the medium risk $27.3 \%$ and for the high risk $59.1 \%$, which was significant $(\mathrm{p}=0.014)$.

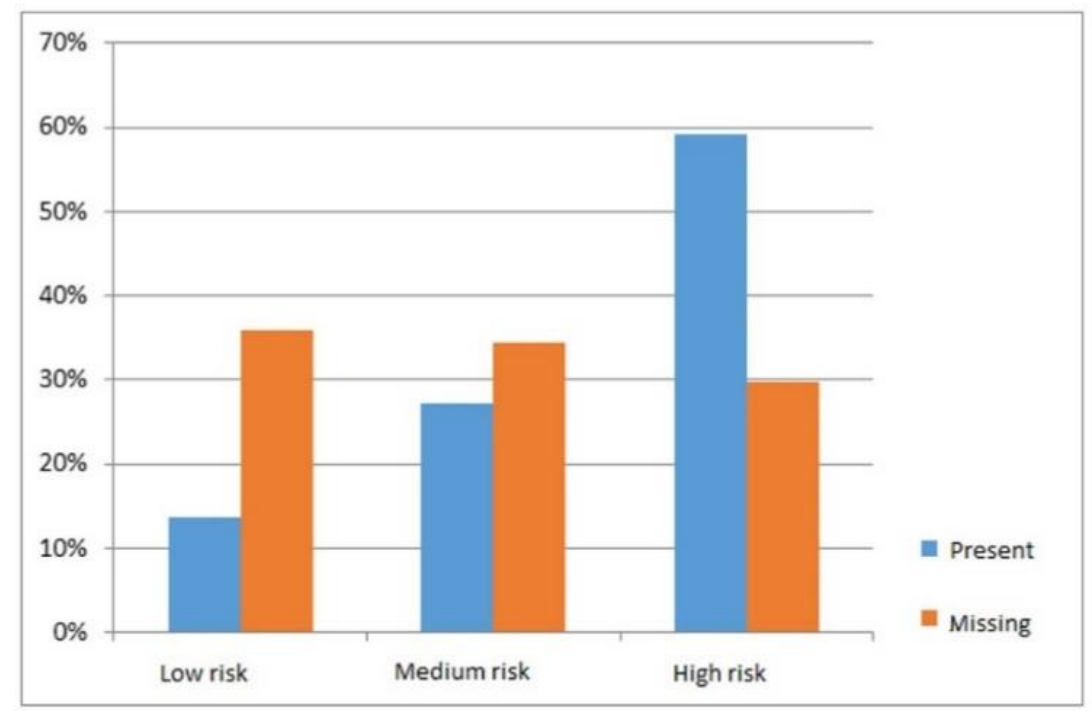

Figure 3: Distribution of patients (VG) according to risk and presence of complications. Bartholomew chi-square test $(\chi 2): \mathrm{p}=$ 0.014

\section{Discussion}

This is one of the studies conducted in Cuba on anesthesia for bariatric surgery with more inclusion of patients, who underwent laparoscopic vertical gastroplication, taking into account the works published in the national literature.

The complications that occurred during the entire perioperative period were few and are mainly focused on those of the cardiovascular and respiratory type. In the literature reviewed there were no incidences of intraoperative or postoperative cardiovascular and/or respiratory complications developed during this type of surgical technique with which it could be compared.

Among the clinical factors that most relate to obesity with cardiovascular disorders are the patient's age, the time of evolution and the time of its appearance, the family pathological history of this condition, the severity of obesity and regional distribution of fat The latter constitutes a risk factor for cardiovascular disease and death, independent of total body fat, since patients with abdominal obesity 
(visceral or central) are more prone to suffer from cardiometabolic disorders, in relation to those where fat accumulates fundamentally gluteal-femoral level (León et al., 2014; López and Cortés, 2011; Cunha et al., 2014).

Cabrera, et al. (2013) in a study carried out in Havana, used the waist-to-hip index of the Cuban tables in order to identify which of the abdominal measurements (W/H I and WC) is the most appropriate for the diagnosis of metabolic syndrome, using different pediatric definitions, in firstdegree relatives of people with type 1 diabetes. They concluded that according to their data, the waisthip index should be used and not the waist circumference suggested by the Latin American Diabetes Association, for the diagnosis of metabolic syndrome.

In a 2014 Spanish study (Fernández et al., 2014), it was shown that the $\mathrm{W} / \mathrm{H}$ index or waist circumference constitute a specific marker of central obesity that together with the association with other diseases such as diabetes mellitus and arterial hypertension are part of the metabolic syndrome with a high degree of complications and cardiovascular mortality.

Thus, it seems increasingly clear that measuring total body fat and using central fat markers such as waist circumference or indexes that involve it would be better than using only BMI. However, in the present investigation it did not turn out to be an independent risk factor.

In obese people, a restrictive respiratory deterioration is characteristic with a decrease in thoracic compliance and pulmonary elasticity. These alterations predispose them to the appearance of respiratory complications during any anesthetic-surgical act (Hatem et al., 2019). If one takes into account that there is a restrictive component due to obesity itself to which an obstructive disease such as bronchial asthma or chronic obstructive pulmonary disease can be added, then it is logical to think that perioperative complications related to these alterations may occur, which can explain what was found in the present investigation.

In the literature reviewed no research was found that seeks to determine the role of alterations in the functional respiratory tests of the obese patient as a risk factor in the occurrence of perioperative complications.

Two studies that evaluate the usefulness of spirometry in predicting postoperative events show weak predictive power and have serious methodological biases (Burgos et al., 2008; Celli et al., 2004). A review with the creation of an evidence-based clinical guide proposed by the American College of Chest Physicians (ACCP) (Brunelli et al., 2013) indicates that the prognostic value as a clinical factor of perioperative risk of forced expiratory volume in the first second (FEV1) preoperative is controversial. 
They recommend other predictive variables such as the diffusion capacity of carbon monoxide, the assessment of exercise capacity with the measurement of maximum oxygen consumption, the walking test for six minutes and the climbing stairs test.

However, other authors (Vargas et al., 2011) indicate that a FEV1 or forced vital capacity (FVC) less than $70 \%$ of the expected value, or a FEV1/FVC ratio less than $65 \%$ are predictors of complications. The predictive value of spirometry varies in different studies with a relative risk for pathological spirometry ranging from 0.9-3.8 and 95\% confidence intervals ranging from 0.5-12.4 (Wang et al., 2017; Al Ghobain, 2012).

Nguyen, et al. (2001) in a study conducted in 70 obese patients operated with gastric bypass via conventional and laparoscopic route, assessed functional respiratory tests on the 1st, 2nd, 3rd and 7th postoperative days, finding that during the first three days with laparoscopic surgery the patients they had significantly less deterioration of lung function in relation to conventional surgery. On the 7th day he finds that the ventilatory parameters had returned to their preoperative level, in those operated by laparoscopic route, not in patients operated by conventional route.

Surgical time is considered an important factor in the association of perioperative complications, since the patient is for a longer time at risk of mechanical ventilation, administration of drugs with varying degrees of cardiovascular depression, infusion of fluids with changes in the internal environment, disorders of temperature, risk of bleeding with use of blood components, among others (Weingarten et al., 2015; Morgan and Ho, 2016).

The prolonged duration of the procedure as a risk factor is supported by most studies. Surgical procedures lasting more than three hours are associated with a high risk of suffering from perioperative complications, especially those of the respiratory type (Moonesinghe et al., 2014). Due to this, it is recommended that the time and surgical procedure be adjusted as much as possible in highrisk patients, such as the morbidly obese.

Total intravenous anesthesia successfully suppresses the stress response, decreases the risk of adverse cardiovascular events, thromboembolism, immune depression, bacterial translocation, infections, tumor spread, among others. On the contrary, inhalation agents do not suppress the stress response, thus depriving the patient of all these advantages (Orozco, 2014).

Several studies (Boveri, 2014; Caballero, 2014) demonstrate the advantages of total intravenous anesthesia (TIVA) over techniques with halogenated agents, since with TIVA less intra and postoperative stress was observed, with significant attenuation of the sympathetic-adrenergic reaction, 
which makes it advantageous for patients with problems cardiovascular and metabolic, as well as lower cortisol levels and lower cytokine release, especially interleukin 6, which is a very sensitive marker of tissue damage.

Although in the last 30 years perioperative mortality decreases due to advances in anesthetic care, surgical techniques and intensive care, determining the predictive factors of complications and mortality of the surgical patient is the tool for the anesthesiologist to adjust and improve the perioperative behavior (Hines, 1992; Bainbridge et al., 2012).

Yurcisin BS, et al. (2009) developed a mortality risk scale in bariatric surgery in which a point value is assigned for each risk factor presented by the patient. In that classification, from 0 to 1 the risk of mortality is $0.2 \%$, from 2 to 3 is $1.1 \%$ and from 4 to 5 is $2.4 \%$.

Khan MA, et al. (2013) evaluated factors capable of predicting perioperative mortality up to 30 days after surgery based on preoperative characteristics of a population of obese patients who required laparoscopic bariatric surgery. They used the database of the American College of Surgeons National Surgical Quality Improvement Program (ACS-NSQIP) to collect all bariatric procedures performed between 2007 and 2009. They identified 44408 patients, 79\% female and 21\% male, with age average $45 \pm 11$ years. Independent predictors associated with significantly increased mortality included age over 45 years, male sex, BMI of $50 \mathrm{Kg} / \mathrm{m}^{2}$ or more, open bariatric procedures, diabetes, functional status of total dependence before surgery, prior coronary intervention, preoperative dyspnea, and blood disorders. Risk stratification based on the number of risk factors showed an exponential increase in mortality as set out below: $0-1$ factor $(0.03 \%), 2-3$ factors $(0.16 \%)$, and 4 or more factors $(7.4 \%)$.

The index constructed in this research on the estimated sample is useful to predict the risk of complications in obese patients treated with laparoscopic bariatric surgery and thus take preventive actions that lead to improvement in their perioperative care. It was possible to validate in an independent sample to that estimated by means of a logistic regression model, with which an ROC curve was constructed that evidenced a good discrimination of the model between patients with and without complications. In this way, an index that classifies patients as high, medium and low risk could be proposed.

Despite the high theoretical anesthetic-surgical risk of the morbidly obese, the results of a multicenter study (National Bariatric Surgery Registry) on 5178 bariatric surgery interventions show a low complication rate $(10.3 \%)$ and a low mortality rate $(0.1 \%)$, similar results to the present investigation. The majority of complications were of respiratory origin and the risk of complications 
was higher in men and was directly related to age and preoperative BMI, but not to the type of intervention (Mason et al., 1992).

Improving the results requires determining the causes and redesigning the treatment strategies of the risk patients. The motivation of the patient against the surgical process, the intraoperative optimization, the adoption of preventive measures of complications, with the aim of reducing the number of organs in post-operative failure are useful (Renshaw et al., 2008).

The problems derived from anesthesia are multifactorial and are basically related to the patient's clinical condition, but also to the selection and conduct of anesthesia (Merry and Mitchell, 2018).

\section{Conclusions}

Three variables were determined that constituted an independent risk factor for the appearance of complications. With the combination of 11 of the explanatory variables considered as potential risk factors for the occurrence of complications, a predictive index was constructed that allowed patients to be classified as low, medium and high risk. The constructed index was validated in a sample different from the estimated one, with a good discrimination power.

\section{Ethical Aspects}

Due to the deliberate non-intervention for experimental purposes for the execution of the project and for the retrospective collection of the data, it was not considered necessary or appropriate to obtain the informed consent of the patients to enter the study, but the anonymity of the data collected, complying at all times with what is established in international and national regulations to safeguard the confidentiality and identity of each patient and only provide results for all of them.

\section{References}

Abete I, Arriola L, Etxezarreta N. Association between different obesity measures and the risk of stroke in the EPIC Spanish cohort. Eur J Nutr 2015; 54: 365-375.

Al Ghobain M. The effect of obesity on spirometry tests among healthy non-smoking adults. BMC Pulmonary Medicine 12: 10 .

Antoniou SA, Antoniou GA, Koch 00, Köhler G, Pointner R, Granderath FA. Laparoscopic versus open obesity surgery: A meta-analisis of pulmonary complications. Dig Surg 2015; 32: 98-107.

Arance M, Docobo F, Conde C, Perez MC, Martin R, Fernandez PE. Es la obesidad un factor de riesgo de complicaciones, ingresos y suspensiones quirurgicas en cirugia mayor ambulatoria? Rev Esp Anestesiol Reanim 2015; 62: 125 -132.

Bainbridge D, Martin J, Arango M, Cheng D. Perioperative and anaesthetic related mortality in developed and 
developing countries: a systematic review and meta-analysis. Lancet 2012; 380.

Blikkendaal MD, Schepers EM, Van Zwet EW, Twijnstra ARH, Jansen FW. Hysterectomy in very obese and morbidly obese patients: a systematic review with cumulative analysis of comparative studies. Arch Gynecol Obstet 2015; 292: 723-738.

Boveri H. ¿Cómo dosificar al obeso mórbido? Rev Mex Anestesiol 2014; 37: S209-S211.

Brunelli A, Kim AW, Berger KI, Addrizzo-Harris DJ. Physiologic evaluation of the patient with lung cancer being considered for resectional surgery: Diagnosis and Management of Lung Cancer. ACCP Evidence-Based Clinical Practice Guidelines (3rd ed). Chest 2013; 143: e166S-e190S.

Buchwald H, Avidor Y, Braunwald E. Bariatric surgery: a systematic review and meta-analisis. JAMA 2004; 292: 17241737.

Builes AM, Ortíz L, Valencia P, López N. Características clínicas, bioquímicas y complicaciones de los pacientes sometidos a la cirugía bariátrica con 18 meses de seguimiento en un hospital de alta complejidad. Iatreia 2019; 32: 16-24.

Burgos AM, Csendes A, Burdiles P, Altuve J, López Y. Función pulmonar pre y post operatoria en bypass gástrico laparotómico y laparoscópico por obesidad mórbida. Rev Chil Cir 2008; 60: 516-523.

Caballero A. Propofol-remifentanilo en cirugía laparoscópica. Rev Mex Anestesiol 2014; 37: S49-S50.

Cabrera E, Cálix WD, Stusser BI, Parlá J, Álvarez A, Olano R, et al. Relación de la resistencia a la insulina con el riesgo cardiovascular, según diferentes tablas y factores de riesgo cardiovascular en sujetos sobrepesos y obesos. Rev Cubana Endocrinol 2013; 24: 136-152.

Celli BR, Cote CG, Marin JM. The body-mass index, airflow obstruction, dyspnea, and exercise capacity index in chronic obstructive pulmonary disease. N Engl J Med 2004; 350: 1005-1012.

Corneille MG, Steigelman MB, Myers JG, Jundt J, Dent DL, Lopez PP, Cohn SM, Stewart RM. Laparoscopic appendectomy is superior to open appendectomy in obese patients. The American journal of surgery 2007; 194: 877-881.

Courcoulas AP, King WC, Belle SH, Berk P, Flum DR, Garcia L, Gourash W, Horlick M, Mitchell JE, Pomp A, Pories WJ. Seven-year weight trajectories and health outcomes in the longitudinal assessment of bariatric surgery (LABS) study. JAMA Surg 2018; 153: 427-434.

Cunha de Oliveira C, Carneiro AK, Eickemberg M, Barreto JM, Barbosa L. Hypertriglyceridemic waist phenotype: association with metabolic disorders and visceral fat in adults. Nutr Hosp 2014; 30: 25-31.

de la Matta M, Acosta J, Sánchez F. Anesthesia for bariatric surgery: 8-Year retrospective study: Are our patients now easier to manage? Rev Esp Anestesiol Reanim 2014; 61: 422-428.

Dimick JB, Cowan Jr JA, Colletti LM, Upchurch Jr GR. Hospital teaching status and out-comes of complex surgical procedures in the United States. Arch Surg 2004; 139: 137-141.

Elffers TW, de Mutsert R, Lamb HJ, de Roos A, Willems van Dijk K, Rosendaal FR, Jukema JW, Trompet S. Body fat distribution, in particular visceral fat, is associated with cardiometabolic risk factors in obese women. PLoS One 2017; 12: e0185403.

Fernández MJ, Basurto L, Córdova N, Vázquez AL, Tepach N, Vega S, et al. La grasa epicárdica se relaciona con la visceral, el síndrome metabólico y la resistencia a la insulina en mujeres menopaúsicas. Rev Esp Cardiol 2014; 67: 436-441.

Gupta PK, Gupta H, Kaushik M, Fang X, Miller WJ, Morrow LE, et al. Predictors of pulmonary complications after bariatric surgery. Surg Obes Relat Dis 2012; 8: 574-581. 
Hatem AM, Ismail MS, El-Hinnawy YH. Effect of different classes of obesity on the pulmonary functions among adult Egyptians: a cross-sectional study. Egypt J Bronchol 2019; 13: 510-515.

Hines HR. Complications ocurring in the postanesthesia care unit: a survey. Anesth Analg 1992; 74: 503-509.

Khan MA, Grinberg R, Johnson S, Afthinos JN, Gibbs KE. Perioperative risk factors for 30-day mortality after bariatric surgery: is functional status important? Surg Endosc 2013; 27: 1772-1777.

Labrada A. Tratamiento anestésico en cirugía laparoscópica en el obeso. En: Carrillo E, de la Paz C. Manejo anestésico del paciente obeso. México. Editorial Alfil, S. A. de C. V. 2012. P: 171-181.

León R, Jiménez BE, López A, Barrera K. Ideas sobre las causas de la obesidad en estudiantes universitarios mexicanos y españoles. Ensen invest Psicol 2014; 19: 149-164.

López F and Cortés M. Obesidad y corazón. Rev Esp Cardiol 2011; 64: 140-149.

Markar SR, Venkat-Raman V, Ho A, Karthikesalingam A, Kinross J, Evans J, Bloom I. Laparoscopic versus open appendicectomy in obese patients. International Journal of Surgery 2019; 9: 451-455

Mason EE, Renquist KE, Jiang D. Perioperative risks and safety of surgery for severe obesity. Am J Clin Nutr 1992; 55: 573-576.

Mason RJ, Moazzez A, Moroney JR, Katkhouda N. Laparoscopic vs Open Appendectomy in Obese Patients: Outcomes Using the American College of Surgeons National Surgical Quality Improvement Program Database. JACS 2012; 215: 88-99.

Merry AF and Mitchell SJ. Complications of anaesthesia. Anaesthesia 2018; 73: 7-11.

Moonesinghe SR, Harris S, Mythen MG, Rowan KM, Haddad FS, Emberton M, et al. Survival after postoperative morbidity: a longitudinal observational cohort study. Br J Anaesth 2014; 113: 977-984.

Morgan DJR, Ho KM. The anaesthetic assessment, management and risk factors of bariatric surgical patients requiring postoperative intensive care support: a state-wide, five-year cohort study. Anaesth Intensive Care 2016; 44: $237-244$.

Nguyen NT, Lee SL, Goldman C, Fleming N, Arango A, McFall R, Wolfe BM. Comparison of pulmonary function and postoperative pain after laparoscopic versus open gastric bypass: a randomized trial. J Am Coll Surg 2001; 192: 469-477.

Orozco R. ¿Qué ofrece la anestesia total intravenosa? Rev Mex Anestesiol 2014; 37: S238-S239.

Puzziferri N, Roshek TB III, Mayo HG, Gallagher R, Belle SH, Livingston EH. Long term follow-up after bariatric surgery: a systematic review. JAMA 2014; 312: 934-942.

Renshaw M, Vaughan C, Ottewill M, Ireland A, Carmody. Clinical incident reporting: wrong time, wrong place. Int J Health Care Qual Assur 2008; 21: 380-384.

Reoch J, Mottillo S, Shimony A, Filion KB, Christou NV, Joseph L, Poirier P, Eisenberg MJ. Safety of Laparoscopic vs Open Bariatric Surgery, A Systematic Review and Meta-analysis. Arch Surg 2011; 146: 1314-1322.

Ribaric G, Buchwald JN, McGlennon TW. Diabetes and weight in comparative studies of bariatric surgery versus conventional medical therapy: a systematic review and meta-analysis. Obes Surg 2014; 24: 437-455.

Ryo M, Funahashi T, Nakamura T, Kihara S, Kotani K, Tokunaga K, Matsuzawa Y, Shimomura I. Fat accumulation and obesity-related cardiovascular risk factors in middle-aged Japanese men and women. Int Med 2014; 53: 101-105.

Sudan R, Winegar D, Thomas S, Morton J. Influence of ethnicity on the efficacy and utilization of bariatric surgery in the USA. J Gastrointest Surg 2014; 18: 130-136. 
Tian HL, Tian JH, Yang KH, Yi K, Li L. The effects of laparoscopic vs. open gastric bypass for morbid obesity: a systematic review and meta-analysis of randomized controlled trials. Obesity Reviews 2011; 12: 254-260

Tinelli R, Litta P, Meir Y, Surico D, Leo L, Fusco A, Angioni S, Cicinelli E. Advantages of laparoscopy versus laparotomy in extremely obese women (BMI> 35) with early-stage endometrial cancer: A multicenter study. Anticancer Research 2014; 34: 2497-2502.

Vargas C, Gochicoa L, Velázquez M, Mejía R, Vázquez JC, Pérez R, et al. Pruebas de función respiratoria, ¿cuál y a quién? Neumol Cir Torax 2011; 70: 101-117.

Wadden TA, Butryn ML, Hong PS, Tsai AG. Behavioral treatment of obesity in patients encountered in primary care settings: a systematic review. JAMA 2014; 312: 1779-1791.

Wang S, Sun X, Hsia T, Lin X, Li M. The effects of body mass index on spirometry tests among adults in Xi'an, China. Medicine (Baltimore) 2017; 96: e6596.

Weingarten TN, Hawkins NM, Beam WB, Brandt HA, Koepp DJ, Kellogg TA, et al. Factors associated with prolonged anesthesia recovery following laparoscopic bariatric surgery: A retrospective analysis. Obes Surg 2015; 25: 1024-1030.

Yurcisin BS, Gaddor MM, DeMaria EJ.Obesity and bariatric surgery. Clin Chest Med 2009; 30: 539-553.

Zerrweck C, Pereyra A, Maydón HG, Fernández I, Campos F, Guilbert L. Remisión a mediano plazo de la diabetes mellitus tipo 2 posterior a cirugía bariátrica en mexicanos: bypass gástrico laparoscópico versus gastroplastia vertical en manga. Rev Mex Cir Endosc 2015; 16. 